\title{
СТРАТИФИКАЦИОННЫЙ ПОТЕНЦИАЛ ИННОВАЦИЙ В ОБРАЗОВАНИИ
}

\author{
(C) 2012 г. Л. В. Илюхина
}

\section{Каменский институт (филиал) \\ Южно-Российского государственного технического университета (НПИ)}

В статье рассматриваются проблемы стратификационного потенциала инноваций в образовании, возросшая значимость критериальности соииальной эффективности, диверсификаџия отношений с внешней сочиильной средой, усиление реализации потенщиала интеграции в общество не только новых образовательных форм, но и устоявшихся социальных отношений.

Ключевые слова: инновации; инновационная деятельность; субъект инновации; социальная дифференциация; стратификационная система; креативность; творческое саморазвитие; адаптивность.

The problems of the innovations'stratification potential for the education, the increased significance of social efficiency's criteria system, diversification of the relations with outer social environment, strengthening the potential of realization of not only new educational forms' but also of the traditional social relations' integration to the society are considered in the article.

Key words: innovations; innovation activity; innovation subject; social differentiation; stratification system; creativity; creative self-development; adaptability.

Достаточно часто в исследовательской практике опривыченное восприятие понятий закрывает скрытые эвристические смыслы, представленные в его сущности. Так и в случае с инновационной проблематикой, которую, как правило, трактуют в тесной связи с внедрением или освоением новшеств, существенно меняющих ту или иную сферу жизнедеятельности человека. При этом результативность инновационного действия представлена через соответствующее совершенствование объекта, на который и направлено это действие.

Так социальные инновации в образовании часто оцениваются только по локальным критериям: функциональности, изменению структур обучения, степени упорядочивания знания, уменьшению социальных и личных затрат. Между тем, необходимо понять, что инновации в образовании не могут рассматриваться изолированно от общесистемного уровня, что навязываемые изменения могут вызвать компенсаторный эффект далеко вы- ходящий за пределы рационально планируемого результата.

В этой связи следует напомнить, что по выражению известного социолога И. Валлерстайна, современность прощается с классической теорией социального модерна. Неопределенность социального развития, глобализация, рационализация, новые общественные движения образуют новую конфигурацию социальных обстоятельств, вследствие чего «Перед началом неопределённости знание предлагает выбор - выбор различного рода» [2]. Картина социальной многомерности мира актуализирует роль образования как сферы рациональности. В словах И. Валлерстайна содержится квинтэссенция современной эпохи: социальная неопределенность обязывает к выбору на основе знания, хотя знание становится конкурирующим, центростремительным, не привязанным к догматике.

Исследование в образовании как структурных, функциональных, институциональ- 
ных параметров, так и различного рода образовательных социальных практик, указывает на возросшую значимость критериальности социальной эффективности, диверсификации отношений с внешней социальной средой, усиление реализации потенциала интеграции в общество не только новых образовательных форм, но и устоявшихся социальных отношений. Именно с этой точки зрения возможно проанализировать эффект взаимодействия инноватики, как становящейся теории и стратификационого подхода, давно сложившегося в рамках классической социологии. Одно из возможных направлений реализации предлагаемого подхода связано с переносом исследовательского акцента на инновационный эффект воздействия не столько на объект нововведения, сколько на те изменения, которые инновационный процесс вызывает в самом субъекте инноваций.

При этом необходимо соблюсти ряд принципиальных методологических условий. В первую очередь речь идет о том, что упорядочивая определённым образом поле субъектного и объектного взаимодействия, важно проанализировать разные уровни субъектного проявления, обеспечивающего инновационный характер развития. На личностном уровне проявления субъектности индивидуализированное отношение субъектов инноваций друг к другу, к содержанию инновации и порождаемым изменениям может проявиться в действиях, суждениях, представлениях, настроениях, ожиданиях, представляет собой специфический сплав сознательного и бессознательного, рационального и эмоционального, систематизированного и бессистемного. Это отношение активно влияет на процесс становления нового, выполняя различные функции: инициатора нововведения, препятствия на его пути и т. п.

Индивидуализированное отношение субъектов к нововведению содержит в себе «в свернутом виде» групповое отношение. Последнее не может быть рассмотрено в виде простой суммы отношений людей, а представляет собой сложное интегративное образование, результат взаимодействия, взаимовлияния и взаимоотражения участников нововведения. Каждый человек формирует, постоянно воспроизводит эти отношения как субъект инноваций, действующий в рамках той или иной организации. Причем именно характер взаимодействия, её направленность и динамика движения к разделяемым ценностям - ориентирам, во многом созидает инновационный потенциал, как личности, так и организации.

Исходя из вышесказанного, дальнейший ход исследования, рассматривающий инновацию как фактор развития образования, может быть конструктивен лишь в случае пересечения двух линий развертывания реальности: одна из них - определение инновации в образовании на основе взаимодействия индивидуумов, выступающих акторами преобразований; другая - деятельностный анализ инновационных возможностей организационных структур, рождающих определённый тип деятельности.

Таким образом, возможно теоретически отрефлексировать как изменение субъекта, связанное с его включением в качестве актора инновационного действия связано с изменением типа его деятельности и влияет на профессионально-статусную позицию. Именно оптимизация этого системного взаимодействия и создаёт инновационный потенциал развития системы образования в целом.

Поскольку базовой категорией анализа выступает деятельность, то обратимся к определению инновационной деятельности. Ю. А. Карпова, опираясь на теоретический анализ различных подходов, сформировавшихся в процессе понимания феномена инновационной деятельности, даёт следующее её определение: «...инновационная деятельность - это метадеятельность, направленная на преобразование всего комплекса личностных средств субъекта, которые обеспечивают не только адаптацию к быстро меняющейся социальной и профессиональной реальности, но и возможность воздействия на неё» $[4$, c. 68$]$.

Отметим два обстоятельства, привлекающие внимание в данном определении. Вопервых, это выход на «метадеятельность», т. е. сущностной характеристикой инновационной деятельности является изменение других деятельностей. Причём, если в управленческом смысле «деятельность по управлению деятельностями», то в инновационном - это действительное изменение сущности самой деятельности. Во-вторых, это выход на по- 
нимание преобразовательного (в противовес адаптивному) характера инновационной деятельности. Можно лишь усилить такое характерологическое отличие переносом акцентов - не только и не столько «адаптацию к...», сколько преобразование социальной и профессиональной реальности. Это подчёркивает природу инновационной деятельности, даёт возможность более полно развести понятия деятельности и процесса.

Инновация проявляет себя как специфическая деятельность по переводу существующих деятельностей в новое качество. Это может происходить постольку, поскольку «деятельность в целом - это органическая система... Непременным признаком органической развивающейся системы является то, что она в процессе своего развития способна к созданию недостающих ей органов» [3, c. 68 ].

Именно так в процессе инновации меняется характер и вид деятельности, вызывая к жизни соответствующий стиль мышления и образ жизни, доминантой которого выступает саморазвитие. Инновационная деятельность реализует не только способность преобразования объекта деятельности. Она создаёт условия «перепрограммирования» оснований или «самостроительства субъекта» (Э. В. Ильенков) в процессе более полного взаимодействия с различными сторонами объекта, поскольку возникающие изменения сущности, структуры, отношений, происходящие при достижении цели, неизбежно вызывают ситуацию неопределённости, в которую попадает субъект, так как «...новые взаимосвязи объекта являются новыми и для него самого» $[3$, с. 68]. При этом используются возможности рационально-рефлексивного сознания, позволяющего произвести «анализ реальной объективной ситуации, её проблемности и возможных путей конструктивного выхода из этой проблемности».

Исходя из этого можно оформить представление о своеобразии инновационного типа личности. С этой точки зрения, привлекает внимание предложенная социологом А. Инкелес аналитическая модель современной личности, значимыми чертами которой являются [4, с. 93-94]: открытость экспериментам, инновациям, изменениям; готовность к плюрализму мнений, призна- ние существования разных точек зрения без опасения изменения собственного видения мира; ориентация на настоящее и будущее, а не на прошлое; уверенность и способность в преодолении создаваемых жизнью препятствий; планирование будущих действий для достижения целей как в общественной, так и в личной жизни; вера в возможность регулирования и прогнозирования социальной жизни; чувство справедливости, основанное на уверенности в зависимости вознаграждения от вклада и мастерства; высокая ценность образования и обучения; уважение достоинства других вне зависимости от статусной позиции.

В той или иной интерпретации, обозначенные черты современной личности, повторяются в работах как зарубежных, так и российских исследователей. В них подчёркивается, что интегральным качеством современной личности является способность не адаптивного самоизменения, когда личность вынуждена приспосабливаться к динамизму социальной жизни, а способность к такому смыслопорождению, которое равно устремлено как на изменение условий социальной жизни, так и на самоизменение. Эта типическая особенность творчества определяет как совокупность личностных черт, так и общие характеристики творческого мышления атрибутивного признака инновационного типа личности. Ведущими свойствами творческого мышления являются: «...способность находить множество разных вариантов решения при одних и тех же условиях; способность находить непротиворечивые решения в противоречивой ситуации» [3, с. 123].

Сочетание этих способностей с соответствующими личностными особенностями составляют сущность такого интегративного качества как креативность, являющаяся необходимым компонентом инновационности.

Практически все исследователи инновационной деятельности объясняют её сущность в тесной связи с позицией творчества: творчества в широком смысле - продуцирование нового принципиально или комбинаций уже известного, в более узком преодоление барьеров стереотипичности, подчиненности влиянию прошлого опыта. Инновационная деятельность неотделима от творчества хотя бы потому, что «качество но- 
вовведения зависит от оригинальности и созидательного мышления одной или нескольких индивидуальностей. Без творчества не может быть нововведения» [11].

Творческий потенциал личности - это интегральная целостность природных и социальных сил человека, обеспечивающих его субъективную потребность в творческой самореализации и саморазвитии. При этом следует уточнение, что структурно-содержательный план творческого потенциала отражает комплекс способностей интеллекта, комплекс свойств креативности, комплекс личностных проявлений, но не сводится к ним. Творческий потенциал педагога следует рассматривать как систему личностных способностей (изобретательность, воображение, критичность ума, открытость ко всему новому), позволяющих оптимально менять приёмы действий в соответствии с новыми условиями, и знаний, умений, убеждений, определяющих результаты деятельности (новизну, оригинальность, уникальность подходов субъекта к осуществлению деятельности), в итоге побуждающих личность к творческой самореализации и саморазвитию [7].

При этом саморазвитие рассматривается как закономерное изменение индивида, т. е. саморазвитие представляет собой как количественные, так и качественные изменения на основе созидательной и творческой деятельности, направленной на поиск оригинальных творческих идей и решений по изменению самого себя. Кроме того, для саморазвития характерны такие существенные отличия, как: а) изменения в личностной сфере детерминированы не извне, а под целенаправленным воздействием личности на самого себя; б) изменения происходят не только в мотивах интеллектуальной, эмоциональной сферах, но и в процессах «самости»: самоопределении, самосовершенствовании, самореализации, самопознании [6]. Главным механизмом как развития, так и саморазвития является разрешение противоречий, решение постоянно усложняющихся творческих задач. В результате саморазвития возникает новое качественное состояние личности и её деятельности, соответствующее процессу актуализации потенциала личности.

Творческое саморазвитие преподавателя - это интегративная характеристика его процессов «самости», среди которых системообразующими компонентами выступают самопознание, творческое самоопределение, самоуправление, самосовершенствование и творческая самореализация личности педагога в его профессионально-творческом становлении [9]. Творческое саморазвитие - это целенаправленно осознаваемый процесс, который охватывает все сферы личности, базируется и всякий раз поднимает на новый уровень функционирования вышеобозначенные процессы «самости». Творческое саморазвитие - это особый вид творчества личности, субъект-субъективной направленности и повышение эффективности, прежде всего, самопознания, творческого самоопределения, творческой самореализации [5]. Исследования показывают, что основную роль в развитии способностей педагога играют его профессиональная деятельность и его стремление к самосовершенствованию [12].

А. И. Пригожин отмечает, что главная характеристика субъекта инноваций - это его деятельное самосознание, т. е. понимание своей личной инициативы как субъективно возможной и общественно принимаемой основы собственного существования. Автор представляет субъектность как единство целеполагания и целеосуществления в одном лице. Субъект есть деятель, способный к выбору типа деятельности, конкретной роли для себя среди других субъектов, к выработке собственных целей и средств для их достижения. Его отличает уверенность, т. е. возможность и желание самому определять свою судьбу, образ жизни, стремление раздвигать рамки реальной независимости и компетентности. Одновременно субъект есть носитель и автор вклада в какую-либо совместную деятельность, партнер в межсубъектных отношениях. Такому пониманию субъекта инноваций А. И. Пригожин противопоставляет зависимого исполнителя («приказчика»), получающего свою компетентность от других и реализующего ее в заданном объёме и режиме [8]. Как видим уже здесь намечается стратификационное различие, характеризующее соответствующую профессиональную позицию.

В тоже время следует отметить, что существующие в образовательной деятельности попытки типизировать субъект инновации на 
личностном уровне, на наш взгляд, на самом деле выражают скорее сложившееся отношение к инновации, нежели собственно инновационную деятельность. Другими словами, в общем массиве педагогических работников определяются группы, тем или иным образом ориентированные на инновацию.

В этом смысле наиболее типичной выступает известная классификация Роджерса, в которой построены идеальные типы «субъектов - реализаторов новшеств» [1]:

- новаторы - всегда открытые к новому; постоянно заряженные на освоение новшеств в собственной практике; хорошо ориентированные в коммуникативном пространстве инноваторов; склонные к риску; осуществляющие свой выбор на основе проектирования процесса получения результата $-2,5 \%$;

- ранние реализаторы - в буквальном смысле следуют за новаторами; ориентированы на их достижения, но без риска; не идут смело за каждым нововведением; расчётливы на основании оценки возможностей полученных результатов нововведений - 13,5\%;

- предварительное больиинство - осваивают уже оправдавшие себя в работе новаторов и ранних реализаторов нововведения; достаточно велика дистанция от ознакомления с оправдавшими себя нововведениями и собственным решением; отличаются высокой степенью свободы выбора; ориентированы на разные варианты действий - 34\%;

- позднее большинство - скептически настроенные по отношению к любому нововведению; к освоению приходят под сильным давлением образовательной среды; в выборе не свободны, поскольку ориентированы только на те нововведения, которые становятся признанными в профессиональной среде; по форме - это простое воспроизводство $34 \%$;

- колеблюшиеся - жесткая ориентация на традиционные ценности и опыт предыдущих поколений; ограниченное коммуникационное поле, способствующее профессиональной замкнутости этой группы; новаторы не пользуются авторитетом и признанием; нововведение осваивается только тогда, когда становится содержательной и организационной нормой $-16 \%$.

Несмотря на определенные достоинства подобной типологии, в основаниях её критериев не удерживаются в качестве сущностных важнейшие отличительные признаки инновации как системы и как специально организованной деятельности. Теряется разница между инновацией как образом жизни, избираемым в результате личного самоопределения и внедрением новшества под давлением обстоятельств. Это не просто отличие творца, производящего новое и ремесленника, воспроизводящего репродукцию, пусть даже высочайшего класса. Истории известны случаи выдающихся подделок, что также выступает своеобразной формой творчества. Здесь противопоставление гораздо более глубокое, на уровне свободы выбора. Возникает противоестественный тип «инноватора поневоле». Однако подобные типологии распространены в российском образовательном пространстве в качестве исследовательского и управленческого инструментария.

Вывод, к которому можно прийти, анализируя данные, отражающие состояние современной образовательной практики, заключается не в сравнении процентных соотношений отдельных групп, представляющих то или иное мнение. Дело в другом: в необходимости типизации многообразия отношений всей совокупности педагогических работников к инновации не на основе вторичных или косвенных признаков (допустим, оценка состояния системы образования), а с учётом степени присвоения инноващионности как качества профессионально-педагогической культурь.

Теоретический анализ практики работы инновационных коллективов и инноваторов в сфере образования, а так же изучение сложившихся подходов в поле социологических исследований этого явления социально-педагогической действительности, убеждает в необходимости выделения на личностном уровне следующих критериальных параметров типологии инновационности как качества профессионально-педагогической культуры:

- во-первых, принята ли инновация как личностно значимая ценность;

- во-вторых, разделяется ли подход к инновации как к необходимому социальному механизму развития системы образования;

- в-третьих, понимается ли инновация 
в качестве целостной системы отношений и специфически организованной деятельности;

- в-четвёртых, переведено ли это отношение в организацию собственной профессиональной деятельности;

- в-пятых, в какой мере в собственной деятельности присвоена специфика инновационной её организации.

C учетом критериальных параметров типологии инновационности на основании содержательной сущности инновации как системы отношений и специфики самоорганизующей и самовоспроизводящей деятельности на личностном уровне, как показало наше исследование, можно обозначить следующие типологические группы:

- инноватор - инновация принята как личностная ценность и присвоена как качество образа жизни - инновационность; инновация, понимаемая в качестве целостной системы, сознательно используется как механизм развития, опирающийся на специально организованную, продуктивную деятельность; полностью реализуется инновационная способность субъекта, сформирована и проявляет себя как качество профессионально-педагогической культуры инновационная деятельность - 8,5\%;

- инновационно-ориентированнылй инновация принята как личностно значимая ценность и рассматривается в качестве механизма развития системы образования; значительная часть инновационных процессов организуется на уровне нововведений, ещё не полностью реализуется представление об инновации как о целостной системе; инновационная способность субъекта используется, преимущественно в форме репродуктивной деятельности; сформировано и проявляет себя как качество профессионально-педагогической культуры инновационное поведение - 17,5\%;

- индифферентный - профессионально значимой ценностью выступает необходимость обновления; представление о механизме развития сформировано преимущественно на уровне снятия «передового педагогического опыта»; новшества и нововведения используются по необходимости, в зависимости о степени и формы стимуляции; инновационная способность проявляется спорадически; сформирована и проявляет себя как качество профессионально-педагогической культуры неопределённость поведения - 48\%;

- консервативно-охранительный профессионально значимой ценностью выступает стабильность, упорядоченность; инновация не принимается ни как способ, ни как средство развития; профессиональная работа, организуется на основе усвоенного опыта предшествующих поколений с ориентацией на требование руководства; новшество осваивается в форме «внедрения»; инновационная способность не проявлена; сформировано и проявляет себя как качество профессионально-педагогической культуры консервативно-охранительное поведение $23 \%$.

Конечно же, предлагаемая типология ещё нуждается в дополнительной апробации, поскольку в ходе нашего исследования были выявлены возможности уточнения сложно дифференцируемого типа индифферентного поведения. Так, внутри типологической группы, по отдельным предметным направлениям инновационных процессов в образовании (допустим, формы, методы и средства организации педагогического процесса) можно было выделить подгруппы «инициативного», «содействующего» и «противодействующего » поведения. Причем как состав, так и удельный вес подгрупп существенно меняется в зависимости от содержательной предметности предлагаемого инновационного изменения.

Однако совершенно очевидно, что субъектная стратификация инновационного действия существенным образом влияет на индивидуальную профессионально-статусную позицию, которая, в свою очередь предопределяет состояние инновационного потенциала образовательной организации. При всем разбросе мнений по поводу сущности этого понятия, в большинстве случаев оно трактуется как определённая степень готовности и способности осваивать, воспроизводить или осуществлять впервые актуальное новшество [10]. Компонентами инновационного потенциала выступают: способность к креативноконструктивной деятельности; способность к саморазвитию; гибкость и адаптивность организационного механизма.

В качестве частных индикаторов состояния инновационного потенциала могут вы- 
ступать определённые социальные качества, к примеру - творческая атмосфера, включающая: положительное отношение к инноваторам, поддержку продуктивных идей, постоянное информирование сотрудников о перспективных новшествах, о положительном отечественном и зарубежном опыте, возможность свободно обмениваться мнениями о положении дел и коллегиально принимать управленческие решения.

Естественно эти показатели могут быть дополнены и другими. В конечном счёте, дело в том, что именно образовательная организация может выступать в качестве коллективного субъекта инновации постольку, только в ней возможно осуществление живого образовательного процесса, позволяющего сохранить образ безграничного мира в ограниченном образовательном пространстве. Она является единственной субъектной «единицей» системы образования, которая минимизирует, но полностью воспроизводит всю совокупность, складывающихся вокруг образовательного процесса, отношений. Следовательно, именно она как микрокосм, может моделировать и реально апробировать, «проживать» социальные механизмы реформирования системы образования и выстраивать прогностические модели будущего общественного устройства.

\section{Литература}

1. Ангеловски К. Учителя и инновации: книга для учителя. - М.: Просвещение, 1991. - C. 45-47.

2. Валлерстайн И. Конец знакомого Поступила в редакциию мира. Социология XXI века. / Пер. с англ. под ред. Б. Л. Иноземцева; Центр исследований постиндустриального общества. - М.: Логос, 2003. - С. 330.

3. Зинченко В. П. Искусственный интеллект и парадоксы психологии. // Природа. 1986. — №2.

4. Карпова Ю. А. Инновации, интеллект, образование. - М., 1998.

5. Морозов А. В. Креативность преподавателя высшей школы. - М., 2002.

6. Морозов A. В. Формирование креативности педагога в условиях непрерывного образования. - М., 2003.

7. Мерзлякова М. Г. Развитие творческого потенциала педагогов в процессе проектирования личностно-ориентированной системы образования в средней школе. - СПб, 1995.

8. Пригожин А. И. Организации: системы и люди. - М., 1986.

9. Рындак В. Г. Взаимодействие процессов непрерывного образования и развития творческого потенциала учителя. - Челябинск, 1996.

10. Сипачев В. В. Экономический механизм управления инновационной восприимчивостью предприятия к достижениям НТП в условиях рыночных отношений. Автореф. ... дисс. канд. эконом. наук. - М., 1997. C. 19 .

11. Твисс Б. Управление научно-техническими нововведениями. - М., 1989. - С. 44.

12. Интеграция науки и практики в развитии творческого потенциала личности учителя и ученика (Материалы республиканской конференции). - Оренбург, 1993.

29 апреля 2012 г. 


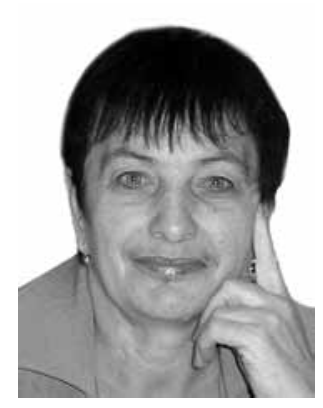

Любовь Васильевна Илюхина - доктор социологических наук, заведующая кафедрой «Гуманитарные дисциплины и экономика», директор Каменского института (филиала) Южно-Российского государственного технического университета (НПИ).

Lubov Vasilievna Ilyukhina - Ph.D., Doctor of Sociology, head of The Humanities and Economics department, director of Kamensk Institute (branch) of South-Russian State Technical University (NPI).

347800, Ростовская обл., г. Каменск-Шахтинский, ул. Сапрыгина, д. 6

6 Saprygina st., 347800, Kamensk-Shakhtinskiy, Rostov reg., Russia

Тел.: +7 (86365) 7-90-86,+7 (86365) 7-90-85; e-mail: kpi@nm.ru, kpi_mail@mail.ru

\section{Гранты 2014 г. (стипендии) для учебы, проведения исследований или стажировки в Швеции}

Фонд Сверкера Острёма(Фонд содействия развитию российско-шведских отношений) сообщает о приеме заявок от российских специалистов на участие в конкурсе стипендий для обучения, проведения исследований или прохождения стажировки (практики) в Швеции.

Стипендии учреждены для того, чтобы дать возможность молодым гражданам Российской Федерации в возрасте от 20 до 35 лет возможность ознакомиться со шведскими достижениями в интересующей их сфере:

- политические науки;

- юриспруденция;

- экономика;

- администрирование;

- искусство.

Кандидаты на получение стипендии должны являться обладателями ученой степени или быть аспирантами.

Информация о Конкурсе на сайте Фонда: http://www.rsci.ru/bitrix/

rk.php?goto=http\%3A\%2F\%2Fwww.sverkerastromfoundation.se $\% 2$ Fsverker_astroms_stiftelse russian\%2Fsverker_astroms_stiftelse_ansok_om_stipendium_ru.asp 